\title{
Prediction of base Isolation Performance on Reinforced Concrete Building
}

\author{
Tuan Norhayati Tuan Chik*, Muhammad Wazien Kamsani, Nor Azizi Yusoff
}

\begin{abstract}
Vibration problems can occur in any buildings due to the surrounding activities and becomes more important issues amongst engineers. The vibration can be induced by internal and external sources around the building. The movement of earthquake can be caused of vibration in the building. The vibration will affect the electronic equipment such as computers and may cause the residents to feel uncomfortable in the building. The objective of this paper is to investigate the performance of base isolator at reinforced concrete building due to low amplitude vibration by using finite element ANSYS software. The prediction on vibration response at structural floor based on performance with base isolator and without base isolator. The presence of base isolator is expected to produce more stable and safe building from any vibration either from internal or external excitation. It will increase the stiffness of the structure and thereby reduces its natural frequency. The building will respond to the seismic activity in a rigid manner rather than resonating with its frequency. In terms of sustainability aspects, it will avoid the damaged buildings from the crack etc. and provide more comfort to the occupants inside the building.
\end{abstract}

Keywords : Base isolator, earthquake, vibration, natural frequency.

\section{INTRODUCTION}

Vibrations in the building came from various sources causing discomfort to the occupants. The external sources will affect the buildings such as rails, buses and trucks. While from internal sources is due to walking activities, aerobic exercise, and mechanical machinery. Vibration usually occurs due to human activity either inside or outside the building. Base isolator allows earthquake forces to be reduced by prolonging the vibration period of the structure. Isolator devices are installed between the base and the structure of the building. In this paper, the chosen building is at the Faculty of Technology Management and Business (FPTP) in Universiti Tun Hussein Onn Malaysia (UTHM). Several complaint have been received from the occupants in this building due to the vibration problems on the certain floor. A few vibration

Revised Manuscript Received on October 22, 2019.

* Correspondence Author

Tuan Norhayati Tuan Chik*, Department of Structural and Material Engineering, Faculty of Civil and Environmental Engineering, Universiti Tun Hussein Onn Malaysia, 86400, Parit Raja, Batu Pahat, Johor, Malaysia. Email: thayati@uthm.edu.my

Muhammad Wazien Kamsani, Department of Structural and Material Engineering, Faculty of Civil and Environmental Engineering, Universiti Tun Hussein Onn Malaysia, 86400, Parit Raja, Batu Pahat, Johor, Malaysia.

Nor Azizi Yusoff, Department of Structural and Material Engineering, Faculty of Civil and Environmental Engineering, Universiti Tun Hussein Onn Malaysia, 86400, Parit Raja, Batu Pahat, Johor, Malaysia. Email: azizy@uthm.edu.my testing has been done and it was concluded that the building having structural problems. Therefore, it is proposed to run several finite element analyses on the differences between base isolator application and conventional building. Hence, the vibration performance of the building can be investigated by using base isolator systems.

\section{LITERATURE REVIEW}

Vibrations propagate into the traffic path environment through geological environments and act as technical seismicity, which includes the surrounding buildings. The history of measured vibrations is used as a burden used for model building structures on a base [1]. Basically, any kind of rotating machine will cause vibration. Vibrations can be transmitted through the structure of the building and can then be seen in another room, from the sources [2]. System vibrations involve energy transfer between potential and kinetic form. In damped systems, some energy is lost in every vibration cycle must be replaced from external sources if vibration is maintained [3].

\section{A. Concept of Vibration}

Any motion that occurs after the interval is called vibration or swing. Swinging the pendulum and pulling the pulled strings is a typical example of vibration. This vibration theory relates to the study of the movements of swinging bodies and the forces associated with them [4]. When the vibrations are transmitted from the source through the ground to the base of the building, they spread to the sides and ups throughout the building. Soil has a strong influence on vibration intensity received inside the building [5]. All bodies with mass and elasticity are able to vibrate. When external forces are used for the body, internal forces are formed in the body that tend to bring the body to its original position. The internal strength is the elastic force that tends to lead the body in a balanced position by considering examples of pendulum oscillators. In this way, vibration motion repeats forever and energy exchanges occur. Movements that occur after acertain interval are called vibrations [6].

\section{B. Vibration Isolation}

Vibration isolation is one of the techniques of vibration control by which the source of vibration excitation and the object to be protected are separated by an auxiliary system consisting of special devices called vibration isolator or vibration isolation mount. Vibration isolation is probably the most commonly used vibration protection approach. It breaks the vibration transmission path from the source to the 
vibration-sensitive device unit or civil engineering structure and improves the performance of the connected objects when properly designed [7]. An isolation system is believed to be active or passive depending on whether external power is needed to perform the function of the isolator. A passive insulator consists of a resilient member, i.e. a damper and a dissipater of energy [8].

\section{Components of a Base Isolated Structure}

A number of buildings have been built around the world using the basic isolation concept for their seismic safety. Fig. 1 shows a performance of the current earthquake has proven the effectiveness of basic isolation techniques [9, 10]. According to Som and Ajay [9] the various isolators, which facilitate the time period shift of the structure to a period range of 2 to 3 seconds, form the isolation system. In base isolated structure, localized non- linearity is observed in the isolation system, while the structural and the soil system are usually assumed to behave linearly. Different designs for base isolator have the same characteristics, the most important are horizontal flexibility and energy dissipation capacity. The basic insulation can reduce the vibration intensity and loss, which directly reduces the shaking intensity and damage caused by permanent equipment and building contents during vibration shaking. Basic isolation is one of the passive energy dissipation techniques for structural vibration resistant design. It is useful for controlling energy, which passes from base or ground to upper stories [10].

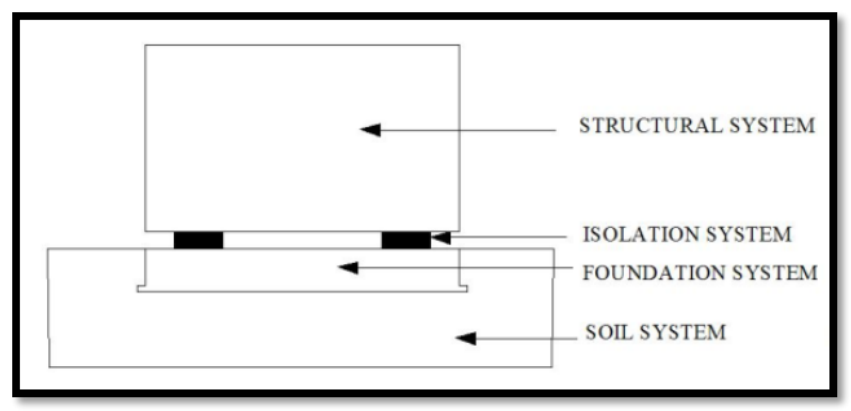

Fig. 1.The components of a base isolated structure

In 1969, a primary school in Skopje, Yugoslavia, first used a rubber isolation system to protect a structure from an earthquake [11]. Fig. 2 indicates the differentiation between conventional structure and base-isolated structure. Since then, the concept of seismic base isolation has been used for decades, the technology is mature and several basic insulation devices are available.

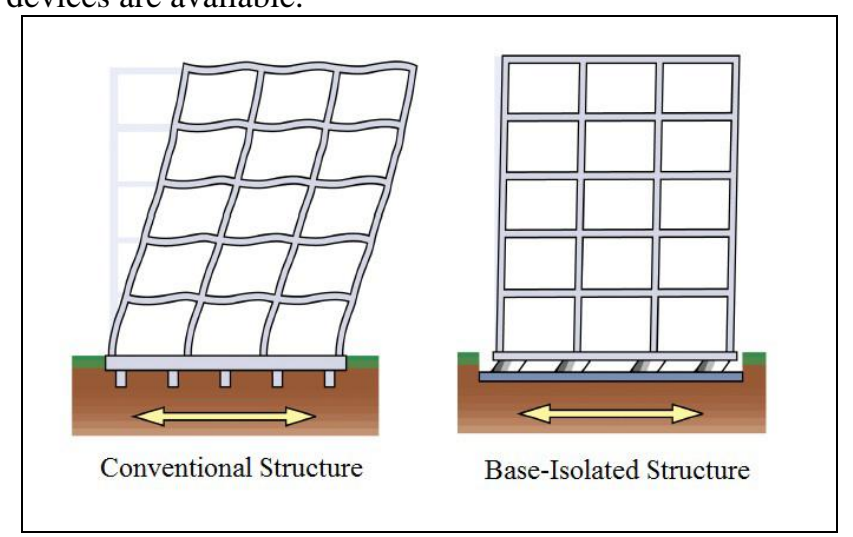

Fig. 2. The effect of vibration to the structure which have base isolation and the conventional

There are two main groups of devices: elastomeric systems and sliding systems. Both insulation systems have some damping, both of which are used to distract the base building frequency beyond the reach of the earthquake, thus reducing the acceleration and the corresponding lateral inertial force [13]. The devices of both groups are defined by a set of specific characteristics such as: the corresponding rigidity and deformation of the load, yield strength and maximum displacement under extreme vibration loads, residual displacement and the ability to return to the initial position [14].

\section{Methods of Base Isolator}

According to Reinhorn, Constantinou \& Nagarajaiah [15], the behavior of the natural bearing of rubber was discussed and examined as it have the ability to provide a large side shift in the early stages of the development of rubber bearings. Some studies have brought significant changes to engineer's attention. Civil engineers and mechanical engineers are therefore attempting to damp in rubber bearings. At the same time, insufficient stiffness considerations have arisen and lead-bearing rubber is created. The lead core can supply high strength rubber layers in vertical direction and is very efficient when the structure is subject to service load [16]. The structure is sufficiently steady and accelerated under the service load and the speed can be controlled within an acceptable range. When structures are subjected to extreme loads, such as large vibrations, rubber layers are produced and energy is transferred to rubber by displacement and absorbed into rubber layers by damping devices [17].

In addition to this new device's good performance, manufacturing costs are also smaller than the cost of enforcing additional power or stiffness controls. The purpose of core rubber bearings are designed to solve problems caused by the burden of service, and it provides direct and economic solutions. Fig. 3 show a lead-plug rubber bearing.

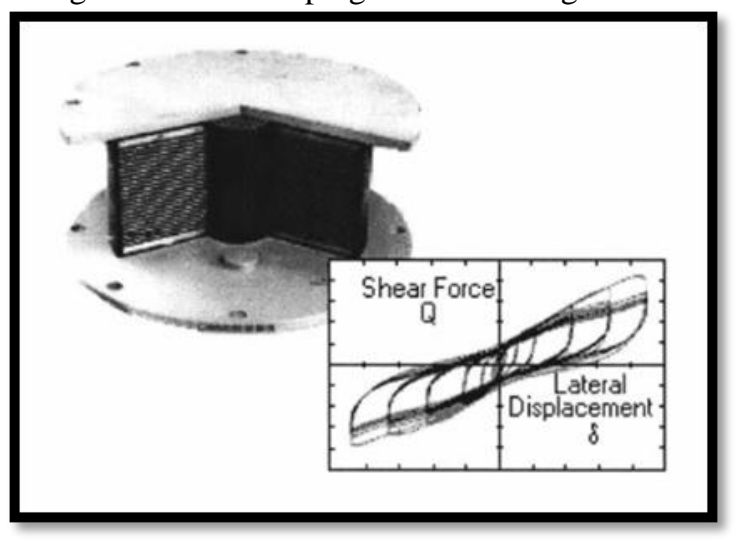

Fig. 3. Shear forces verses lateral displacement of lead-plug rubber bearing

\section{FINITE ELEMENT MODELLING WITH ANSYS}

The developed finite element was applied to run modal analysis and transient modal analysis to determine the natural frequencies and the mode shape of the structure.

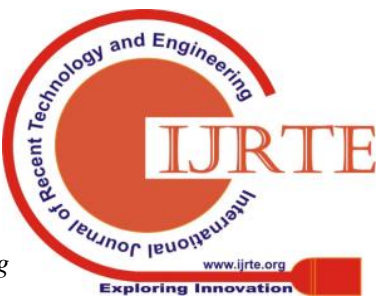


High number of modes are obtained to investigate the behavior of the floor. Transient analysis was done due to transient nature of loading. There are two methods available to do the transient analysis and they are mode superposition and direct integration method. There are five important codes which need to be provided in ANSYS when using code (command method) as listed as in Table-I.

Table-I: Preprocessing in ANSYS

\begin{tabular}{|c|c|l|}
\hline Step & Analysis & \multicolumn{1}{c|}{ Description } \\
\hline 1 & Parameters & $\begin{array}{l}\text { Specifies building structure } \\
\text { such as size of beam, column } \\
\text { size, floor size, height of } \\
\text { buildings and others }\end{array}$ \\
\hline 2 & Geometry & $\begin{array}{l}\text { An elemental code is necessary } \\
\text { to model the building }\end{array}$ \\
\hline 3 & Meshing & $\begin{array}{l}\text { Establish network or } \\
\text { deployment of structural } \\
\text { elements. Mesh size according } \\
\text { to the size of the structural } \\
\text { elements that are applied to } \\
\text { each structure }\end{array}$ \\
\hline 4 & $\begin{array}{c}\text { Degree of } \\
\text { freedom } \\
\text { (DOF) }\end{array}$ & $\begin{array}{l}\text { It is the main point of study on } \\
\text { the floor because there is no } \\
\text { change in every direction }\end{array}$ \\
\hline 5 & Modal & $\begin{array}{l}\text { Modal analysis is to obtain } \\
\text { natural frequencies and mode } \\
\text { shapes of the building. }\end{array}$ \\
\hline
\end{tabular}

\section{A. Modal Analysis}

Modal analysis is an analysis of the dynamic features in the frequency field. Every object has its own internal frequency, which can naturally vibrate. When the load frequency is the same as the structure's natural frequency, the energy is transferred with a minimum loss. The effects of changes in the young module, density, length and cross-sectional areas on the change in frequency and the shape of the natural structure mod differ. The bar length uncertainty produce the largest impact on the natural frequency of the structure, however, the density uncertainty, the cross-sectional area and the length has the same effect on the change in structural mode [18]. Natural frequencies and modes are vulnerable to system changes in system parameters such as mass and stiffness, the overall structural state is monitored [19].

\section{B. Build the Model}

The finite element analysis (FEM) method for loads and determines the structure of the building's structure against a load. Structures are modelled using discrete elements and nodes. In each element there is an equation to determine the reaction of the load to be charged. The size and length of beam is shown in Table-II, while Table-III it shows the properties of the constituent element used in the model. Steel reinforcement has been used for the structural material. The concrete density was assumed to be $2500 \mathrm{~kg} / \mathrm{m}^{3}$. Besides that, dynamic modulus of elasticity of concrete was taken as $38 \mathrm{GPa}$. Poisson ratio for concrete was assumed to be 0.2 . The concrete graded at $40 \mathrm{~N} / \mathrm{mm}^{2}$. The beam, column, and spring element were modelled in ANSYS by using BEAM4 element, for the mass using element MASS21, spring element
COMBIN14, while the reinforced concrete slab was modelled by using SHELL63 element.

Table-II: Exact size of beam and length of the building

\begin{tabular}{|c|c|c|}
\hline Floor & Size beam $(\mathrm{m})$ & Length beam $(\mathrm{m})$ \\
\hline \multirow{3}{*}{ Ground floor } & $0.20 \times 0.75$ & 8.50 \\
& $0.20 \times 0.60$ & 8.10 \\
& $0.30 \times 0.75$ & 9.50 \\
\hline \multirow{3}{*}{ First floor } & $0.20 \times 1.20$ & 5.65 \\
& $0.30 \times 0.75$ & 9.50 \\
& $0.20 \times 0.60$ & 6.70 \\
\hline \multirow{3}{*}{ Second floor } & $0.40 \times 0.85$ & 9.50 \\
& $0.30 \times 0.75$ & 9.50 \\
& $0.20 \times 0.85$ & 6.00 \\
\hline
\end{tabular}

Table -III: Properties of circular isolator

\begin{tabular}{|c|c|c|c|}
\hline \multirow{2}{*}{ Materials } & \multirow{2}{*}{$\begin{array}{c}\text { Density } \\
\left(\mathrm{kg} / \mathrm{m}^{3}\right)\end{array}$} & $\begin{array}{c}\text { Elastic } \\
\text { Modulus } \\
(\mathrm{GPa})\end{array}$ & $\begin{array}{c}\text { Poisson } \\
\text { Ratio }\end{array}$ \\
\hline Concrete masonry unit & 2500 & 38 & 0.2 \\
Slab & 3250 & 38 & 0.2 \\
Steel bar & 7850 & 38 & 0.2 \\
\hline
\end{tabular}

\section{Geometrical Properties of Base Isolator}

The finite element of the circular isolator is analyzed by using ANSYS14.0. Geometrical properties of circular isolator are listed in Table-IV.

Table-IV: Properties of circular isolator

\begin{tabular}{|c|c|}
\hline \multicolumn{2}{|c|}{ Circular isolator } \\
\hline Diameter & $305 \mathrm{~mm}$ \\
\hline Total height & $141 \mathrm{~mm}$ \\
\hline Thickness of fibre layer & $3 \mathrm{~mm}$ \\
\hline Number of fibre layer & 13 \\
\hline Thickness of rubber layer & $8.5 \mathrm{~mm}$ \\
\hline Number of rubber layer & 12 \\
\hline $\begin{array}{c}\text { Bonded end plate } \\
\text { diameter }\end{array}$ & $305 \mathrm{~mm}$ \\
\hline Un-bonded end plate & $340 \mathrm{~mm}$ \\
\hline $\begin{array}{c}\text { Un Un-bonded end plate } \\
\text { thickness (Top and } \\
\text { bottom) }\end{array}$ & $15 \mathrm{~mm}$ \\
\hline
\end{tabular}

\section{RESULTS AND DISCUSSIONS}

\section{A. Modelling of Building}

The FPTP building needs to be modelled first before the input data generated from the observation data is included in the building model. The building has three floors and each structure of this building is modelled in ANSYS based on the original plan as indicated in Fig. 4. All the original values and sizes on columns and beams have been applied and used.

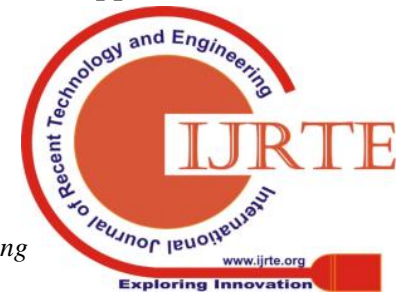




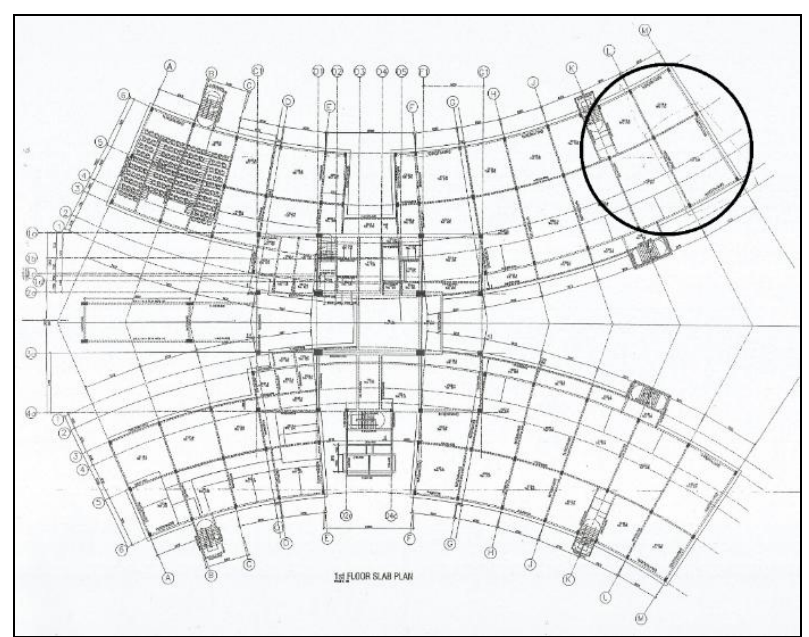

Fig. 4. Original floor plan (FPTP Building)

Fig. 5 shows the building in three storey consists of floors, beams and columns generated by modal analysis according to the original building plan provided. It shows final meshing structures with the applied base isolators.

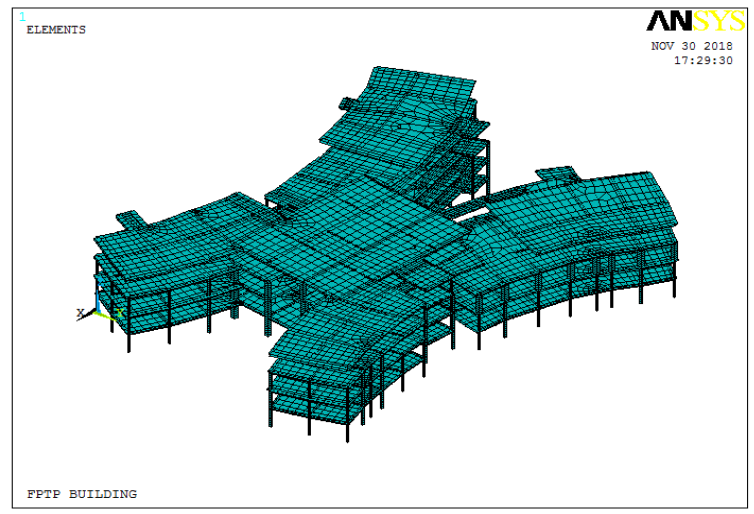

Fig. 5. Building structure in ANSYS

\section{B. Modal Analysis}

It is about 100 mode shapes have been obtained in modal analysis to produce natural frequencies and the behavior of the floor of the building in a vertical mode. Two analyses were carried out which are the building without base isolator and building with base isolator. Each mode shapes on the floor of the building is dependent on the frequency produced. There are four colors in mode shapes which are blue is defined as no movements occur, green is defined as the minimum movement, yellow is defined as the movement of the moderate and red is defined as the maximum movement. Mode shape on the lower floor of the building has not significantly change because it is near the base of the building.

Fig. 6 shows the deformation of mode and natural frequency on the building. It can be seen that more mode shapes are obtained, the higher the frequency generated. Mode 1 is categorized as a fundamental mode, which is the most important mode to emphasize in another analysis. It shows a significant different with and without base isolator. Mode 1 has $0 \mathrm{~Hz}$ for building with base isolator, but $0.64 \mathrm{~Hz}$ without base isolator. The value of lowest mode is too small to see the behavior of the floor and building. Hence, higher mode should be obtained in order to perform better structural behavior as shown in Mode 31, Mode 51, Mode 71 and Mode
99. In Mode 99, the natural frequency is $7.63 \mathrm{~Hz}$ without base isolator. However the natural frequency is lower when applying the base isolator which is $3.88 \mathrm{~Hz}$. This is because when the mass increased with the base isolator underneath the building, the frequency become lower. It is reduced the acceleration value of motion corresponding excitation force into the structure. The presence of base isolator reduced the value of frequency and provide structure become more flexible [14].

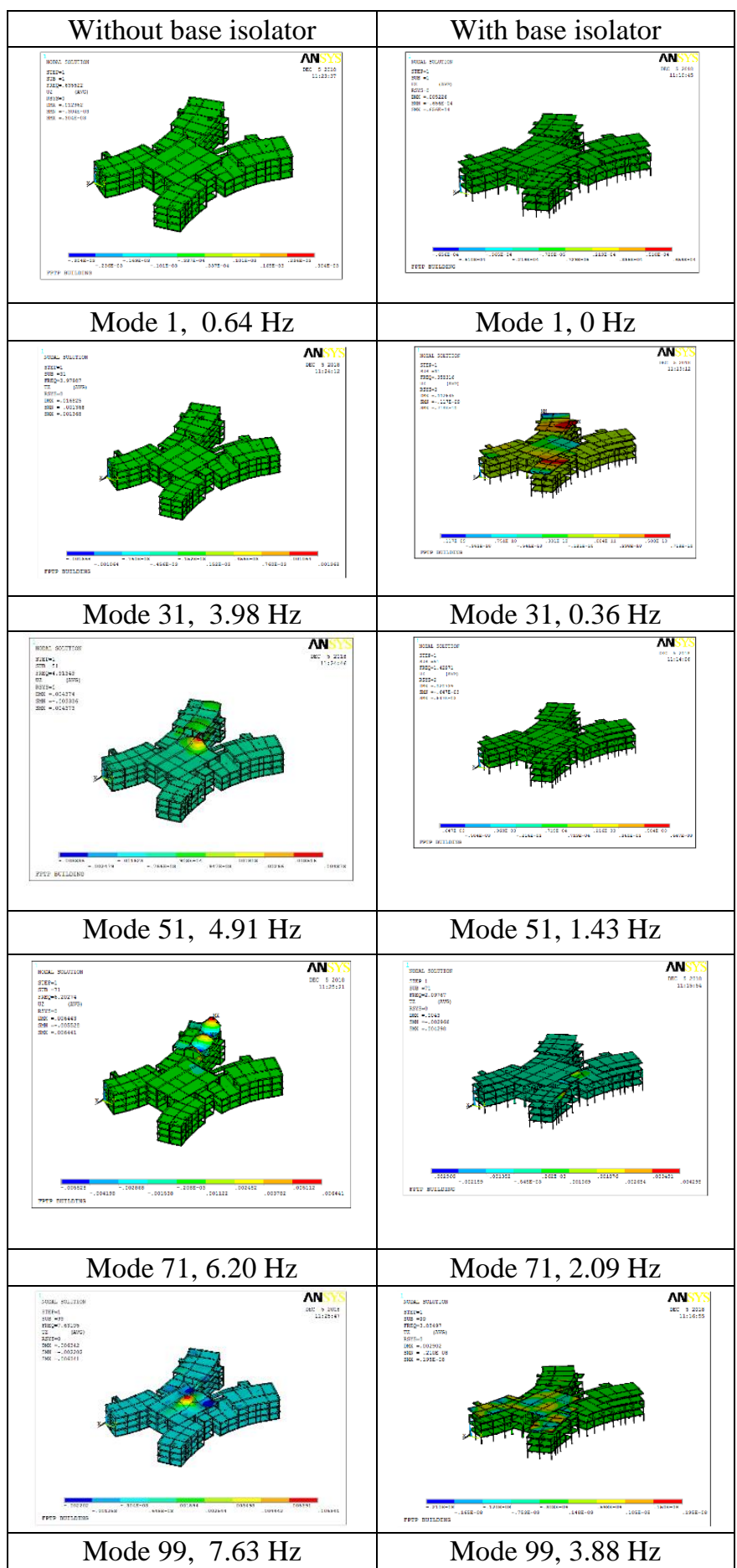

Fig. 6. Mode shape and natural frequency values for each selected modes 


\section{CONCLUSIONS}

As a conclusion in this paper, the building applied with base isolator produce lower natural frequency compared with the building without base isolator. The structure of the building is more stable if it uses base isolator. The base isolator is the best solution for the area which is prone to earthquake effect or having bigger vibration. Although there is no big earthquake recorded in Malaysia, however it can have the effect from neighboring country like Indonesia. Therefore this study is become as preliminary research or earlier guidance due to ground vibration in order to perform the base isolator effect for the building.

\section{ACKNOWLEDGMENT}

This research work is supported by the TIER 1 Grant code H259 at Universiti Tun Hussien Onn Malaysia (UTHM), Batu Pahat, Johor.

\section{REFERENCES}

1. D. Makovic`ka, "Structure isolation in order to reduce vibration transfer from the subsoil", Klokner Institute, Czech Technical University in Prague, Czech Republic, 2014.

2. Satis Paul de vos, "Railway induced vibration", International union of railway, Paris. 2017.

3. R. E. Blake, Basic vibration theory. Harris' Shock and Vibration Handbook. 2002.

4. Y. Zhang and A. Tang, "New approach for vehicle system NVH: A new concept in generation of clean and renewable energy from fluid flow". 2006.

5. J. H. Rainer, "Vibrations in buildings", National Research Council Canada, Division of Building Research, Canada. 1984.

6. V. Woosye, "What is the basic concept of vibration". 2012.

7. E. I. Rivin, "Passive vibration isolation", Marcel Dekker Inc., New York. 1999.

8. C. Du, and L. Xie, "Modelling and control of vibration in mechanical systems data storage". Institute Singapore, Nanyang Technological University Singapore. 2010

9. G. K. Som, and K. S. Ajay, "Seismic assessment and analysis of base isolated building", Department of Civil Engineering, S.S.G.I. (F.E.T.) Bhilai (India). 2017.

10. A. Verma, G. Ashutosh, and B. N. Prof, "Base isolation system: a review”, Civil Engineering Department, MMMUT Gorakhpur, India, Director, GEC Mainpuri, India. 2017.

11. E. Staudacher, C. Habacher, and R. Siegenthaler, "Erdbebensicherung in Baum," Neue Zurcher Zeitung, Technikbeilage, Zurich, Switzerland. 1970.

12. M. Efiloglu, "Understanding the concept of base isolation", Engineering Structural Master, The University of Manchester. 2013.

13. S. Manarbek, "Study of base isolation systems", Bachelor of Engineering in N. S. W Department of Environment and Conservation. 2012.

14. A. R. Kamble, A. C. Omkar, S. K. Mahaveer, K. K. Harish, and S. Shantanu, Magdum, "Seismic analysis of symmetric building with base isolation technique", S.I.T.C.O.E Yadrav/ Shivaji University, India 2017.

15. M. Reinhorn, M. C. Constantinou and S. Nagarajaiah. "Torsion in Base-Isolated Structures With Elastomeric Isolation Systems", Journal of Structural Engineering. 1993. Vol. 119, No. 10, pp. 2932-2951.

16. N. Makris, "Rigidity-plasticity-viscosity: can electro rheological dampers protect base-isolated structures from near-source ground motions", Earthquake Engineering and Structural Dynamics, 1997, Vol. 26, pp.5 7 1-591.

17. J. M. Kelly, "The role of damping in seismic isolation", Earthquake Engineering and Dynamics, 1999, Vol. 28, Issue 1, pp. 3-20.

18. W. Gao, "Natural frequency and mode shape analysis of structure with uncertainty". School of Mechanical and Manufacturing Engineering, The University of New South Wales, Sydney, Australia. 2006.

19. S. Hassiotis and G. D. Jeong, "Identification of stiffness reduction using natural frequencies". Journal of Engineering Mechanics. 1995.

\section{AUTHORS PROFILE}
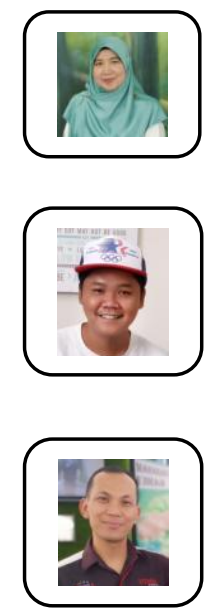

Tuan Norhayati Tuan Chik, Department of Structural and Material Engineering, Faculty of Civil and Environmental Engineering, Universiti Tun Hussein Onn Malaysia, 86400, Parit Raja, Batu Pahat, Johor, Malaysia.

Muhammad Wazien Kamsani, Department of Structural and Material Engineering, Faculty of Civil and Environmental Engineering, Universiti Tun Hussein Onn Malaysia, 86400, Parit Raja, Batu Pahat, Johor, Malaysia.

Nor Azizi Yusoff, Department of Structural and Material Engineering, Faculty of Civil and Environmental Engineering, Universiti Tun Hussein Onn Malaysia, 86400, Parit Raja, Batu Pahat, Johor, Malaysia. 